\title{
Comparative Analysis of the Performance of Six Models for the Estimation of Global Solar Radiation for Katsina, Nigeria
}

\author{
Garba Musa Argungu ${ }^{1,}$, , Yusuf Abubakar Sanusi ${ }^{1}$, Kabir Ahmed Dabai ${ }^{1}$, Muazu Abubakar ${ }^{1}$, \\ Abubakar Roko \\ ${ }^{1}$ Department of Physics, Usmanu Danfodiyo University, Sokoto, Nigeria \\ ${ }^{2}$ Department of Computer Science, Usmanu Danfodiyo University, Sokoto, Nigeria
}

Email address:

garba.musa@udusok.edu.ng (G. M. Argungu)

*Corresponding author

\section{To cite this article:}

Garba Musa Argungu, Yusuf Abubakar Sanusi, Kabir Ahmed Dabai, Muazu Abubakar, Abubakar Roko. Comparative Analysis of the Performance of Six Models for the Estimation of Global Solar Radiation for Katsina, Nigeria. American Journal of Energy Engineering. Vol. 8, No. 2, 2020, pp. 18-25. doi: 10.11648/j.ajee.20200802.11

Received: June 10, 2020; Accepted: June 22, 2020; Published: July 13, 2020

\begin{abstract}
Solar radiation data is an essential pre-requisite for the designing, sizing and performing evaluation of any solar energy conversion system in any part of the globe, even though solar radiation data are not readily available for many location of many developing countries such as Nigeria, hence the needs to rely on empirical models. There are many developed models across the globe for the estimation of solar radiation, to identify the optimum performing model for locations such as Katsina requires the comparism between the various models. In this study, performance evaluation of six selected models for the estimation of global solar radiation was carried out for Katsina location, Nigeria. The models were formed from different combinations of some meteorological parameters (sunshine hours, relative humidity and temperatures) obtained for a period of ten years (2006-2015) from Nigerian Meteorological Agency (NIMET). Monthly average extraterrestrial global solar radiation was evaluated for the locations. The data was analysed to find the empirical constants for all the selected models in the locations. Estimated values of global solar radiation was obtained from the six selected models. The estimated values were then compared using statistical parameters (mean bias error (MBE), mean percentage error (MPE), root mean square error (RMSE) and coefficient of determinant $\left(\mathrm{R}^{2}\right)$. Model 6 was found to be the optimum model for Katsina because it fitted the measured data most for each month of year based on various statistical parameters used for the analysis.
\end{abstract}

Keywords: Radiation, Extraterrestrial, Energy, Meteorological and Evaluation 1, Introduction

\section{Introduction}

It is becoming glaringly clear that energy demand may not be met by sources from fossil fuels alone as such the need to complemented energy sources from fossil fuels with sources from that of renewable which are sustainable and environmentally friendly such as solar and wind. This is because the availability of cheap, sustainable and abundant supply of energy is not only an index of measuring standard of living of any nation, but also an indicator of its level of Industrialization [1]. Increase in population coupled with technological advancement cause the demand for energy to increase both in developed and developing countries [2]. The progress of a nation is sometimes compared in terms of per capita consumption of energy i.e. the amount of energy consumed per person per year [3]. Energy comes from many sources and most of these energy sources are substitutable to one another due to the fact that energy can be converted from one form of energy to another- such as: Coal to electricity, Use of photo-electricity to derive a chemical reaction, Wind energy to pump and store water that could be used to produce electricity when required, Solid biomass to produce liquid or gaseous fuels of higher calorific value, etc. [4].

Almost all the energy sources originate entirely from the sun. In general, the sun supplies the energy absorbed in the short term by the earth's atmosphere and oceans but in the 
long term by the lithosphere where the fossil fuels are embedded [5]. Another aspect of solar energy is the interception of sunlight by plants and is transformed by photosynthesis into biomass. Solar energy can be tapped directly (solar thermal and solar photovoltaic) or indirectly as with wind biomass and hydropower; or as fossil fuels such as coal, oil and natural gas. Sunlight is by far the largest carbonfree energy source in the planet [4]. Solar radiation is the most important natural energy resource because it drives all environmental processes acting at the surface of the Earth. The sun is an internal energy generator and distributor responsible for most of our easily accessible energy resources including oil, coal, etc [3].

Solar radiation is a primary driver for many physical, chemical, and biological processes on the earth's surface. Solar energy engineers, architects, agriculturists, hydrologists, etc. often require a reasonable accurate knowledge of the availability of the solar resource for their relevant applications at their locality. In solar applications, one of the most important parameters needed is the long-term average daily global radiation for regions where no actual measured values are available. Almost all the energy sources originate entirely from the sun. In general, the sun supplies the energy absorbed in the short term by the earth's atmosphere and oceans but in the long term by the lithosphere where the fossil fuels are embedded [5].

Another aspect of solar energy is the interception of sunlight by plants and is transformed by photosynthesis into biomass. Solar energy can be tapped directly (solar thermal and solar photovoltaic) or indirectly as with wind biomass and hydropower; or as fossil fuels such as coal, oil and natural gas. Sunlight is by far the largest carbon-free energy source in the planet [4]. Solar radiation is the most important natural energy resource because it drives all environmental processes acting at the surface of the Earth. The sun is an internal energy generator and distributor responsible for most of our easily accessible energy resources including oil, coal, etc [3] 8. Solar radiation is a primary driver for many physical, chemical, and biological processes on the earth's surface. Solar energy engineers, architects, agriculturists, hydrologists, etc. often require a reasonable accurate knowledge of the availability of the solar resource for their relevant applications at their locality. In solar applications, one of the most important parameters needed is the long-term average daily global radiation for regions where no actual measured values are available.

Solar energy is the ultimate source of energy that is infinite, environmentally friendly and in-exhaustible for any practical application. However, solar radiation data is basic necessities for performance and evaluation of any solar energy systems. The best way to collect solar radiation is to set up a weather measuring stations at the desired locations of interest but these is not easy for all practical desired locations even in developed countries talkless of developing nations such as Nigeria. The alternative approach is to correlate the global radiation with the meteorological parameters where the data can be collected [6].
A common practice is to estimate average daily global solar radiation using appropriate empirical correlations models based on the measured relevant data at those locations. These correlations estimate the values of global solar radiation for a region of interest from more readily available meteorological, climatological, and geographical parameters.

The aim of this research is to evaluate and compare the performance of six selected models for estimation of global solar radiation using various meteorological parameters for Katsina, in Northwest, Nigeria.

\subsection{Estimation of Global Solar Radiation Techniques}

The first correlation proposed for the estimating of the monthly average daily global radiation is based on the method of Angstrom, the original Angstrom-Prescott type regression equation-related monthly average daily radiation to clear day radiation in a given location and average fraction of possible sunshine hours is given by $[5,7]$ as:

$$
\frac{H}{H_{o}}=a+b\left(\frac{S}{S_{o}}\right)
$$

Where:

$\mathrm{H}$ the monthly average daily global radiation on a horizontal surface;

$\mathrm{H}_{\mathrm{o}} \quad$ monthly average daily extraterrestrial radiation on

$\mathrm{H}_{\mathrm{o}} \quad$ a horizontal surface;

$\mathrm{S}$ monthly average daily hours of bright sunshine;

$\mathrm{S}_{\mathrm{o}} \quad$ monthly average day length;

$a, b$ are known as Angstrom constants and they are empirical.

The correlation used for evaluation of monthly average clearness index is as used by [8]:

The clearness index $\left(K_{t}=\frac{H}{H_{O}}\right)$

\subsection{Theoretical Consideration}

Solar researchers have developed many empirical correlations which determine the relation between solar radiation and various meteorological parameters. The parameters used as the input of radiation model are the most important key to choose the proper radiation model at any location [2].

Empirical models can be mainly classified into four categories based on the employed meteorological parameters:

Sunshine-based models.

Cloud-based models.

Temperature-based models.

Other meteorological parameter-based models.

Among all such meteorological parameters, bright sunshine hours, relative humidity and temperature are the most widely and commonly used ones to predict global solar radiation and its components at any location of interest [9]. Solar radiation models can also be classified as: Linear Models and Non-linear Models; depending on the type of relationships between the parameters. 
Table 1. The linear and None linear regression models and their sources.

\begin{tabular}{lll}
\hline S/N & Model Equation & Source. \\
\hline 1 & $\frac{H}{H_{o}}=a+b\left(\frac{S}{S_{o}}\right)$ & {$[5]$} \\
2 & $\frac{H}{H_{o}}=c+e\left(\frac{S}{S_{o}}\right)+f\left(\frac{T_{\min }}{T_{\max }}\right)+g\left(\frac{R H}{R H_{\max }}\right)$ & {$[10]$} \\
3 & $\frac{H}{H_{o}}=h+i\left(\frac{S}{S_{o}}\right)+j(R H)$ & {$[11]$} \\
4 & $\frac{H}{H_{o}}=k\left(\frac{S}{S_{o}}\right)^{l}$ & {$[12]$} \\
5 & $\frac{H}{H_{o}}=m+n\left(\frac{S}{S_{o}}\right)+o \exp \left(\frac{S}{S_{o}}\right)$ & {$[13]$} \\
6 & $\frac{H}{H_{o}}=p\left(\frac{S}{S_{o}}\right)^{q} T_{\text {max }}^{r} R H^{s}$ & {$[10]$} \\
\hline
\end{tabular}

Where,

$H \quad$ Monthly average daily global radiation on

horizontal surface

$H_{o} \quad$ Monthly average daily extraterrestrial

radiation on horizontal surface

$S \quad$ Monthly average daily bright sunshine duration

$S_{o} \quad$ Monthly average maximum possible daily

sunshine duration

$T_{\min } \quad$ Mean minimum daily temperature

$T_{\max } \quad$ Mean maximum daily temperature

$R H \quad$ Mean relative humidity

$R H_{\max } \quad$ Maximum relative humidity

$a-r \quad$ are regression coefficients

\subsection{Extraterrestrial Solar Radiation}

Some variation in the extraterrestrial solar radiation above the atmosphere are not due to solar changes but rather to the earth sun distance throughout the year, the monthly average extraterrestrial solar radiation on a horizontal surface $\left(\mathrm{H}_{\mathrm{o}}\right)$ can be computed from the following equation $[14 ; 15]$ :

$$
H_{o}=I_{s c}\left(\frac{24}{\pi}\right) E_{o}\left[\left(\frac{2 \pi \omega_{s}}{360}\right) \sin \Phi \sin \delta+\cos \Phi \cos \delta \sin \omega_{s}\right]
$$

Where,

$H_{o} \quad$ is the extraterrestrial solar radiation on horizontal

surface

$I_{s c} \quad$ is solar constant $=1367 \mathrm{~W} / \mathrm{m}^{2}$

$n \quad$ is the $n^{\text {th }}$ day of the year ( $\operatorname{Jan} 1=1$; Dec $\left.31=365\right)$ is the Earth's Eccentricity Factor $=1+$

$E_{o} \quad 0.033 \cos \left(\frac{360 d n}{365}\right)$

$\Phi \quad$ Latitude of the location

$\delta \quad$ Declination $=23.45 \sin \left[\frac{360}{365}(d n+284)\right]$

$w_{s}$ is sunset hour angle in degrees $=\cos ^{-1}-$

$w_{s} \tan \delta \tan \phi$

\subsection{Statistical Test Parameters}

The results obtained from various models (linear and nonlinear) will be compared with measured values through the following statistical test:

\subsubsection{Mean Bias Error (MBE)}

The mean bias error (MBE) provides information on the long-term performance of the correlations by allowing a comparison of the actual deviation between calculated and measured values term by term, the ideal value of the MBE is zero, the MBE is given by:

$$
M B E=\frac{1}{K} \sum_{i=1}^{k}\left(y_{i}-x_{i}\right)
$$

Where, $y_{i}$ is the $i^{\text {th }}$ calculated values; $x_{i}$ is the $i^{\text {th }}$ measured value, and $k$ is the total number of observations.

\subsubsection{Root Means Square Error (RMSE)}

The root mean square error (RMSE) is a frequently used measure of the differences between values predicted by a model or an estimator and the values actually observed from the thing being modeled or estimated. RMSE is a good measure of precision. The value of RMSE is always positive, representing zero in the ideal case. The RMSE may be computed from the following equation.

Where, $y_{i}$ is the $i^{\text {th }}$ calculated values; $x_{i}$ is the $i^{\text {th }}$ measured value, and $k$ is the total number of observations

$$
R M S E=\left[\frac{1}{K} \sum_{i=1}^{k}\left(y_{i}-x_{i}\right)^{2}\right]^{\frac{1}{2}}
$$

\subsubsection{Mean Percentage Error (MPE\%)}

The mean percentage error (MPE) is the computed average of percentage errors by which forecasts of a model differ from actual values of the quantity being forecast.

$$
M P E \%=\frac{1}{K} \sum_{i=1}^{k}\left(y_{i}-x_{i}\right) \times 100
$$

Where $\mathrm{y}_{i}$ is the actual value of the quantity being forecast, $\mathrm{x}_{i}$ is the forecast, and $\mathrm{k}$ is the number of different times for which the variables is forecast.

\subsubsection{Mean Relative Error (MRE)}

The MRE can be used to test for determining the linear relationship between measured and estimated values.

Where, $y_{i}$ is the $i^{\text {th }}$ calculated values; $x_{i}$ is the $i^{\text {th }}$ measured value, and $n$ is the total number of observations

$$
M R E=\frac{1}{n} \sum_{i=1}^{n}\left|\frac{y_{i}-x_{i}}{x_{i}}\right|
$$

\subsubsection{Correlation Coefficient ( $r$ )}

The Pearson correlation coefficient often referred to as the Pearson $r$ test, is a statistical formula that measures the strength between variables and relationships, to determine how strong the relationship is between two variables, you need to find the coefficient value which can range between 0.01 and 1.00 .

$$
R=\frac{\sum_{i=1}^{k}\left(y_{i}-\bar{y}\right)\left(x_{i}-\bar{x}\right)}{\left[\sum_{i=1}^{k}\left(y_{i}-\bar{y}\right)^{2} \sum_{i=1}^{k}\left(x_{i}-\bar{x}\right)^{2}\right]^{\frac{1}{2}}}
$$

\subsubsection{Coefficient of Determinant $\left(R^{2}\right)$}

The coefficient of determinant $\left(\mathrm{R}^{2}\right)$ is a key output of regression analysis. It is interpreted as the proportion of the variance in the dependent variable that is predictable from the independent variable. 


$$
R^{2}=1-\frac{\sum_{i=1}^{k}\left(x_{i}-y_{i}\right)^{2}}{\sum_{i=1}^{k}\left(x_{i}-\bar{x}\right)}
$$

Where, $y_{i}$ is the $i^{\text {th }}$ calculated values; $x_{i}$ is the $i^{\text {th }}$ measured value, and $k$ is the total number of observations.

The models with close value of $\mathrm{R}$ and $\mathrm{R}^{2}$ to 1 , and least value of RMSE and MPE will be said to be a better fit to the measured data at each of the selected location.

\section{Materials and Method}

The ten years daily (2006-2015) average solar radiation sunshine hours, relative humidity, maximum relative humidity, maximum and minimum temperatures for the study area was obtained from Nigerian Meteorological Agency (NIMET), Abuja Nigeria. The geographical co-ordinates of the location is as shown in Table 2.

Table 2. Geographical Co-ordinates of the locations.

\begin{tabular}{lllll}
\hline S/N & Location & Latitude & Longitude & Altitude \\
\hline 1 & Katsina & $12.5139^{\circ} \mathrm{N}$ & $7.6114^{\circ} \mathrm{E}$ & $513 \mathrm{~m}$ \\
\hline
\end{tabular}

The data was summarized and presented in table 3, which is used in the carefully selected models.

\subsection{Formation of Parametric Equations}

From the selected six selected models (three linear and other three non-linear models), the non-linear models were however transformed to linear and then method of least square error was used to form the parametric equations for all the models as follows:

\subsection{Parametric Equations for Model 1}

This model is the Angstrom-Prescott model involving only sunshine duration given as:

$$
\frac{H}{H_{o}}=a+b\left(\frac{S}{S_{o}}\right)
$$

Its parametric equations were formed as:

$$
\begin{gathered}
\sum \frac{H}{H_{o}}=a n+b \sum\left(\frac{S}{S_{o}}\right) \\
\sum \frac{H}{H_{o}} \cdot \frac{S}{S_{o}}=a \sum \frac{S}{S_{o}}+b \sum\left(\frac{S}{S_{o}}\right)^{2}
\end{gathered}
$$

\subsection{Parametric Equations for Model 2}

This model is a Linear Model involving Sunshine hour, temperature in degree Celsius and Relative humidity expressed as:

$$
\frac{H}{H_{o}}=c+d\left(\frac{S}{S_{o}}\right)+e\left(\frac{T_{\min }}{T_{\max }}\right)+f\left(\frac{R H}{R H_{\max }}\right)
$$

Its parametric equations were formed as:

$$
\begin{gathered}
\sum \frac{H}{H_{o}}=c n+d \sum\left(\frac{S}{S_{o}}\right)+e \sum\left(\frac{T_{\min }}{T_{\max }}\right)+f \sum\left(\frac{R H}{R H_{\max }}\right) \\
\sum \frac{H}{H_{o}} \cdot \frac{S}{S_{o}}=c \sum\left(\frac{S}{S_{o}}\right)+d \sum\left(\frac{S}{S_{o}}\right)^{2}+e \sum\left(\frac{S}{S_{o}} \cdot \frac{T_{\min }}{T_{\max }}\right)+f \sum\left(\frac{R H}{R H_{\max }} \cdot \frac{S}{S_{o}}\right) \\
\sum\left(\frac{H}{H_{o}} \cdot \frac{T_{\min }}{T_{\max }}\right)=c \sum \frac{T_{\min }}{T_{\max }}+d \sum\left(\frac{S}{S_{o}} \cdot \frac{T_{\min }}{T_{\max }}\right)+e \sum\left(\frac{T_{\min }}{T_{\max }}\right)^{2}+f \sum\left(\frac{R H}{R H_{\max }} \cdot \frac{T_{\min }}{T_{\max }}\right) \\
\sum\left(\frac{H}{H_{o}} \cdot \frac{R H}{R H_{\max }}\right)=c \sum\left(\frac{R H}{R H_{\max }}\right)+d \sum\left(\frac{S}{S_{o}} \cdot \frac{R H}{R H_{\max }}\right)+e \sum\left(\frac{T_{\min }}{T_{\max }} \cdot \frac{R H}{R H_{\max }}\right)+f \sum\left(\frac{R H}{R H_{\max }}\right)^{2}
\end{gathered}
$$

\subsection{Parametric Equations for Model 3}

This model is a linear model involving sunshine hours and relative humidity expressed as:

$$
\frac{H}{H_{o}}=g+h\left(\frac{S}{S_{o}}\right)+j(R H)
$$

Its parametric equations were formed as:

$$
\begin{gathered}
\sum \frac{H}{H_{o}}=g n+h \sum \frac{S}{S_{o}}+j \sum(R H) \\
\sum \frac{H}{H_{o}} \cdot \frac{S}{S_{o}}=g \sum\left(\frac{S}{S_{o}}\right)+h \sum\left(\frac{S}{S_{o}}\right)^{2}+j \sum(R H) \cdot\left(\frac{S}{S_{o}}\right) \\
\sum \frac{H}{H_{o}} \cdot(R H)=g \sum(R H)+h \sum \frac{S}{S_{o}} \cdot(R H)+j \sum(R H)^{2}
\end{gathered}
$$

\subsection{Parametric Equations for Model 4}

This model is a non-linear model involving sunshine hour expressed as: 


$$
\frac{H}{H_{o}}=k\left(\frac{S}{S_{o}}\right)^{l}
$$

Its parametric equations were formed as:

$$
\begin{gathered}
\sum \ln \frac{H}{H_{o}}=n \ln k+l \sum \ln \left(\frac{S}{S_{o}}\right) \\
\sum \ln \left(\frac{H}{H_{o}}\right) \cdot \ln \left(\frac{S}{S_{o}}\right)=\ln k \sum \ln \left(\frac{S}{S_{o}}\right)+l \sum\left(\ln \frac{S}{S_{o}}\right)^{2}
\end{gathered}
$$

\subsection{Parametric Equations for Model 5}

This model is a non-linear model involving multi-sunshine hour expressed as:

$$
\frac{H}{H_{o}}=m+p\left(\frac{S}{S_{o}}\right)+q \exp \left(\frac{S}{S_{o}}\right)
$$

Its parametric equations were formed as:

$$
\begin{gathered}
\sum \frac{H}{H_{o}}=m n+p \sum\left(\frac{S}{S_{o}}\right)+q \sum \exp \left(\frac{S}{S_{o}}\right) \\
\sum\left(\frac{H}{H_{o}} \cdot \frac{S}{S_{o}}\right)=m \sum\left(\frac{S}{S_{o}}\right)+p \sum\left(\frac{S}{S_{o}}\right)^{2}+q \sum\left(\exp \left(\frac{S}{S_{o}}\right)\right)^{2} \\
\sum\left(\frac{H}{H_{o}}\right) \cdot \exp \left(\frac{S}{S_{o}}\right)=m \sum \exp \left(\frac{S}{S_{o}}\right)+p \sum\left(\frac{S}{S_{o}}\right) \cdot \exp \left(\frac{S}{S_{o}}\right)+q \sum\left(\exp \left(\frac{S}{S_{o}}\right)\right)^{2}
\end{gathered}
$$

\subsection{Parametric Equations for Model 6}

This model is a non-linear model involving sunshine hour, temperature in degree Celsius and relative humidity expressed as:

$$
\frac{H}{H_{o}}=r\left(\frac{S}{S_{o}}\right)^{q} T_{\max }^{r} R H^{s}
$$

Its parametric equations were formed as:

$$
\begin{gathered}
\sum \ln \left(\frac{H}{H_{o}}\right)=n \ln r+s \sum \ln \left(\frac{S}{S_{o}}\right)+t \sum \ln \left(T_{\text {max }}\right)+u \sum \ln (R H) \\
\sum \ln \left(\frac{H}{H_{o}}\right) \ln \left(\frac{S}{S_{o}}\right)=\ln r \sum \ln \frac{S}{S_{o}}+s \sum\left(\ln \left(\frac{S}{S_{o}}\right)\right)^{2}+t \sum \ln \left(T_{\max }\right) \ln \left(\frac{S}{S_{o}}\right)+u \sum \ln (R H) \ln \left(\frac{S}{S_{o}}\right) \\
\sum \ln \left(\frac{H}{H_{o}}\right) \ln \left(T_{\text {max }}\right)=\ln r \sum \ln \left(T_{\text {max }}\right)+s \sum \ln \left(\frac{S}{S_{o}}\right) \ln \left(T_{\max }\right)+t \sum\left(\ln \left(T_{\text {max }}\right)\right)^{2}+u \sum \ln (R H) \ln \left(T_{\text {max }}\right) \\
\sum \ln \left(\frac{H}{H_{o}}\right) \ln (R H)=\ln r \sum \ln (R H)+s \sum \ln \left(\frac{S}{S_{o}}\right) \ln (R H)+t \sum \ln \left(T_{\text {max }}\right) \ln (R H)+u \sum(\ln (R H))^{2}
\end{gathered}
$$

The empirical constants evaluated by solving the parametric equations were obtained and results substituted in to the relevant correspondent models for the Katsina Location:

$$
\text { Model 1: } \frac{H}{H_{o}}=-0.24+1.331\left(\frac{S}{S_{o}}\right)
$$

$$
\begin{gathered}
\text { Model 2: } \frac{H}{H_{O}}=0.566+1.013\left(\frac{S}{S_{o}}\right)+(-0.650)\left(\frac{T_{\min }}{T_{\max }}\right)+(-0.280)\left(\frac{R H}{R H_{\max }}\right) \\
\text { Model 3: } \frac{H}{H_{o}}=0.264+0.820\left(\frac{S}{S_{o}}\right)+(-0.004)(R H) \\
\text { Model } 4: \frac{H}{H_{O}}=1.178\left(\frac{S}{S_{o}}\right)^{1.495}
\end{gathered}
$$




$$
\begin{gathered}
\text { Model 5: } \frac{H}{H_{o}}=-0.281+1.402\left(\frac{S}{S_{o}}\right)+(-0.002) \exp \left(\frac{S}{S_{o}}\right) \\
\text { Model 6: } \frac{H}{H_{o}}=6.456\left(\frac{S}{S_{o}}\right)^{0.795} T_{\max }{ }^{-0.308} R H^{-0.251}
\end{gathered}
$$

\section{Results and Discussions}

The extraterrestrial solar radiation calculated for the locations is as shown in the Table 3.

Table 3. Extraterrestrial Solar Radiation in $\mathrm{kWh} / \mathrm{m}^{2}-$ day for the Locations.

\begin{tabular}{ll}
\hline Months & Katsina \\
\hline Jan & 30.781 \\
Feb & 33.696 \\
Mar & 36.460 \\
Apr & 38.029 \\
May & 38.087 \\
Jun & 37.726 \\
Jul & 37.732 \\
Aug & 37.817 \\
Sep & 36.842 \\
Oct & 34.353 \\
Nov & 31.373 \\
Dec & 29.805 \\
Average & 35.225 \\
\hline
\end{tabular}

The yearly average measured data for solar radiation, sunshine hours, relative humidity, maximum relative humidity, maximum and minimum temperature for Katsina locations is as shown in Table 4.

Table 4 The Yearly Average Data Values for Katsina.

\begin{tabular}{lllllll}
\hline Months & $\mathbf{S}$ & $\mathbf{H}$ & $\mathbf{R H}$ & $\mathbf{R H}_{\max }$ & $\mathbf{T}_{\min }$ & $\mathbf{T}_{\max }$ \\
\hline Jan & 8.03 & 24.64 & 26.38 & 37.48 & 13.89 & 29.96 \\
Feb & 8.55 & 26.29 & 18.94 & 32.27 & 16.86 & 34.28 \\
Mar & 7.45 & 26.01 & 16.26 & 29.28 & 20.28 & 36.98 \\
Apr & 7.58 & 24.13 & 27.28 & 51.50 & 24.07 & 39.12 \\
May & 7.98 & 20.80 & 45.24 & 70.00 & 25.88 & 38.47 \\
Jun & 7.65 & 19.15 & 55.70 & 74.70 & 24.34 & 35.98 \\
Jul & 7.32 & 18.33 & 67.45 & 85.55 & 22.24 & 32.51 \\
Aug & 6.98 & 18.14 & 76.44 & 90.52 & 21.48 & 30.39 \\
Sep & 7.92 & 20.27 & 68.44 & 82.52 & 22.10 & 32.57 \\
Oct & 8.71 & 22.93 & 49.09 & 74.65 & 21.86 & 35.18 \\
Nov & 8.94 & 25.11 & 28.46 & 42.78 & 17.41 & 24.12 \\
Dec & 8.44 & 24.47 & 29.52 & 39.55 & 13.76 & 29.97 \\
Average & 7.96 & 22.52 & 42.43 & 59.23 & 20.35 & 33.29 \\
\hline
\end{tabular}

The solar radiation was estimated using the six selected models and results obtained is compared with the monthly average measured values for Katsina locations as shown in figure 1.

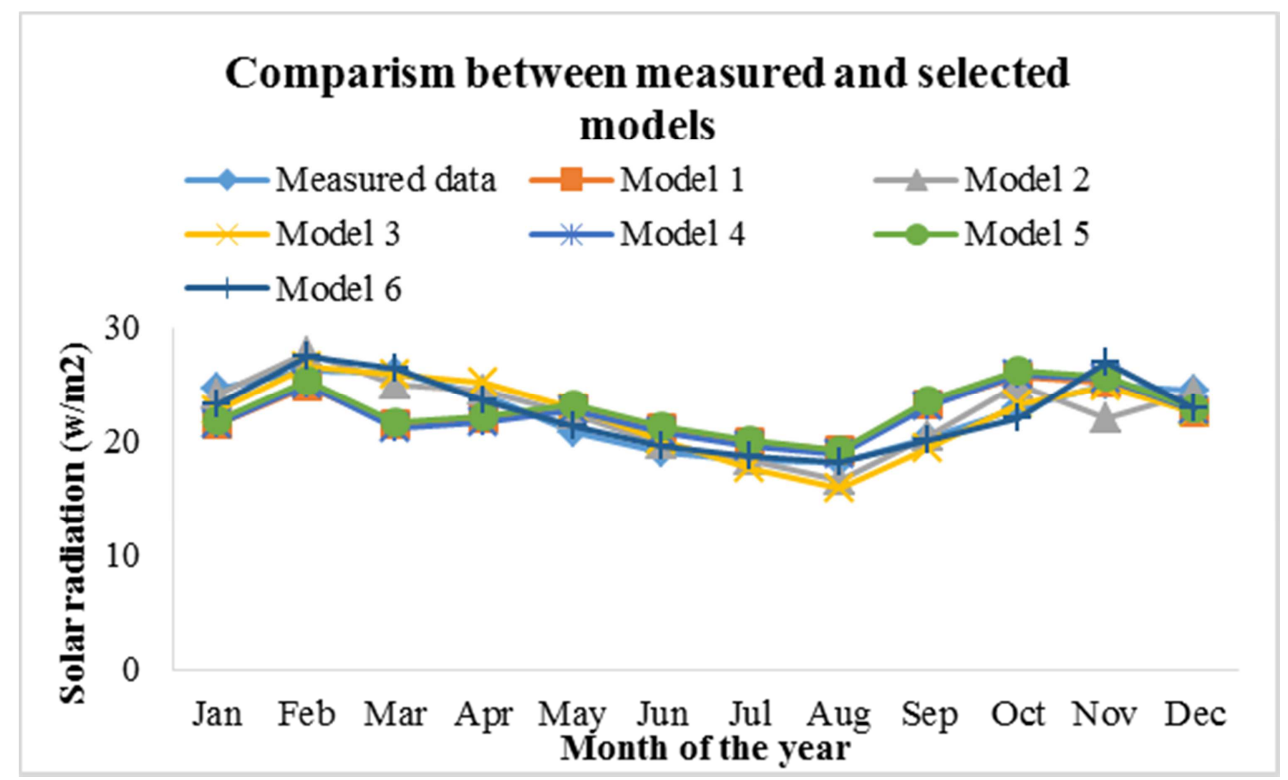

Figure 1. Comparism of the Monthly estimated Solar Radiation from the six models with monthly average measured global solar radiation for Katsina. The accuracy of the models where compared using the following statistical parameters presented in Table 5.

The performance of each of the six selected models were compared using the statistical indicators mentioned above. Generally low values of MBE, RMSE, MPE and MRE are desirable for better performance, while the value of $R^{2}$ closer to unity (1) indicates a good performance. The RSME test provides information on the short-term performance, the
MBE, MPE test provides information on the long-term performance. Positive values on the other hand is an indication of over estimates for MBE, RMSE, MPE and MRE and vice versa [16]. The results obtained from the statistical test is presented in table 5 below. 
Table 5. Statistical Analysis of the Models for Katsina Location.

\begin{tabular}{|c|c|c|c|c|c|c|}
\hline Statistical parameters & Modell & Model2 & Model3 & Model4 & Model5 & Model 6 \\
\hline MBE & 0.011 & 0.056 & -0.241 & -0.087 & 0.288 & 0.0453 \\
\hline RMSE & 2.398 & 1.399 & 1.299 & 2.379 & 2.400 & 0.9633 \\
\hline MPE & 1.095 & 5.567 & 24.07 & -8.668 & 28.81 & 4.5314 \\
\hline MRE & 0.011 & 0.003 & -0.012 & 0.005 & 0.023 & 0.0024 \\
\hline $\mathrm{R}^{2}$ & 0.323 & 0.797 & 0.843 & 0.350 & 0.340 & 0.9982 \\
\hline
\end{tabular}

\subsection{Comparism Between the Selected Models Using the Figure}

It is very clear from the figure 1 above that model 6 is much closer to the monthly measured values than the remaining models as can be seen is from January to December with model 1 as least performing with other models in between the two models.

\subsection{Comparism Between the Selected Models}

As can be seen from table 5, only model 3 gave negative values of MBE, MPE and MRE while model 4 gave negative value of MBE and MPE, which is an indication of underestimation. The other models that gave positive values with highest value of MPE of 28.8077 by model 5, indicating most overestimated and lowest positive value of 0.0024 from MRE by model 6 indicating least overestimated. Since the closer to zero the values of MBE, MPE and MRE the better the performance of the models, model 6 can still be said to be better, since it has closer values to zero for both MBE and MRE and second to model 1 in the case of MPE.

The values of the root mean square error (RMSE) is an indication of the differences between values predicated by the models and values obtained from the actual measurement. It is also a very good measure of precision. The value of RMSE is always positive representing zero in the optimum performance, however, for this analysis model 6 , is still the best performing model followed by model $3,2,4,5$ and model 1. The mean percentage error (MPE) is the computed average of percentage errors by which forecast of model differ from the actual values measured. The smaller the value the better the performance. From the results obtained model 1 has the least value of MPE followed by model 6,2, 4, 3 and model 5 being the least performing. In the case of mean relative error (MRE) which can be used in determining the linear relationship between measured and estimated values, which means the smaller the value of MRE the better the performance of the model. The model 6 performed better using this indicator followed by model 2, 4, 1, 3 with model 5 being the least performing. Finally the coefficient of determinant $R^{2}$ usually interprets the proportion of the variance in the dependent variable that is predicated from the independent variable. Its values ranges from o to 1 , with 1 indicating perfect correlation. From the results obtained model 6 is the best performing model followed by model 3 , 2, 4, 5 with model 1 being the least performing model.

Generally speaking all the six models performed reasonably better when compared with the monthly measured values of solar radiation data as can be seen in figure 1 . However, comparing the models, model 6 can be said to be the optimum performing model with lowest value of RMSE and MRE as well as having values of $R^{2}$ closest to unity (1) followed by model 2, 1, 4, 3 with model 5 as the least performing model in the location.

\section{Conclusion}

From the six model selected for this analysis, three linear and three non-linear models considered both models performed reasonably well when compared with the monthly average values of solar radiation measured for Katsina location.

However, model 6 appeared to be the best performing model compared to the other models followed by model 2,1 , 4, 3 and model 5 the least performing using the 5 statistical models.

All the six models can be used depending on the available metrological parameters available to reasonably estimate the monthly average global solar radiation for Katsina location.

For a precise estimation of monthly average solar radiation data model 6 is recommended.

\section{References}

[1] Abdulrahim, A. T., Diso, I. S., El-jummah A. M. (2011) A Simple Correlation to Estimate Global Solar Irradiation on a Horizontal Surface using Meteosat Satellite Images. Constant Journal of Engineering Science, 6 (3) 30-37.

[2] Nwokoye, A. O., and Ike, C. U. (2003) Measurement of Global Radiation Constant "Intensity"Awka, using Pyranometer, Nigeria. Journal on Renewable Energy, 11 (1\&2) 1-8.

[3] Innocent, A. J., Jacob, O. B., Chibuzo, G. C., James, I. and Odeh, O. (2015) Estimation of Global Solar Radiation in Gusau, Nigeria. International Journal of Research in Engineering and Technology, ISSN: 2347-4599.

[4] Sen, Z. (2008) Solar Energy Fundamental and Modeling Technique, Atmosphere, Environment, Climate Change and Renewable Energy, Istanbul, Turkey, Springer Verlag, London, 34469 .

[5] Duffie, J. A. and Beckman, W. A. (2013) Solar Engineering of Thermal Processing, 4th Ed. Madison: John Wiley \& Sons, Inc.

[6] Krishna R, Adhikaril, Binod K. Bhattarai I, Shekhar Gurun (2013) "Estimation pof Global Solar Radiation for Four Selected Sites in Nepal Using Sunshine Hours, Temperature and Relative Humidity" Journal of Power and Energy Engineering 1, 1-9. 
[7] Gana, N. N. and Akpootu, D. O. (2013) Estimation of Global Solar Radiation using Four Sunshine Based Models in Northwestern Nigeria, Journal Advance in Applied Science Research, 4 (5): 409-421.

[8] Vecan, D. (2011) Measurement and Comparison of Solar Radiation estimation Models for Izmir, Turkey. International Journal of Science and Technology, 4 (1) 1943-2429.

[9] Korachagaon, I. B., Bapat, V. N., and Anjum, M. I. (2008) Predicting Global Solar Radiation for South America. International Journal of Mechanical Meter Eng, ISSN: 2 (3), 139.

[10] Besharat, F., Dehghan, A. A., and Faghih, A. R. (2013) Empirical Models for Estimating Global Solar Radiation in Yazd City, Iran, Proceedings of the "International Conference on Solar Energy for MENA region (INCOSOL)" Amman, Jordan, 22-23 October Paper Number: 2 (1).

[11] Kacem Gairaa and Yahia Bakelli (2013) A Comparative Study of Some Regression Models to Estimate the Global Solar Radiation on a Horizontal Surface from Sunshine Duration and Meteorological Parameters for Gharda / a Site, Algeria Hindawi Publishing Corporation ISRN Renewable Energy http://dx.doi.org/10.1155/2013/754956
[12] Bakirci, K. (2008) Correlation for Estimating of Solar Radiation on Horizontal Surface. Journal of Energy Engeering, ISSN: 134 (4), 130-4.

[13] Bakirci, K., Pandey, C. K. (2010) Simple Correlation for Estimating the Global Solar Radiation on Horizontal Surface in India. Journal of Thermal Science and Technology in india, 3 (1) $60-71$.

[14] Fariba Beshatrat, Ali A, Dehghan, Ahmed R. Faghih (2013) Empirical models for the estimating global solar radiation: A reviews and case study Renewable and sustainable energy Reviews Elsevier 21 (2013) 798-821.

[15] Foster, R., Ghassemi, M., Cota, A. (2010) Determination of the Optimal Tilt Angle for Solar Photovoltaic Panel in Ilorin, Nigeria. Solar Energy Renewable Energy and the Environment, $1^{\text {st }}$ Ed. Boca Raton: Taylor \& Francis Group. Inc.

[16] Gairaa, K., Bakelli, Y. (2011) An Overview of Global Solar Radiation Measurement in Ghardaia Area, South Algeria. International Journal of Energy and Environment, 2 (2) 255260. 